\title{
Food habit of the adolescents in relation with socio-demographic variables in a selected high school in Khulna City
}

\author{
S Paroi ${ }^{1}$, ABMA Islam ${ }^{2}$, MA Hasanat ${ }^{3}$, FT Zohora ${ }^{4}$
}

\begin{abstract}
Background: The actions, reactions, and thoughts of an individual are influenced by other people or groups. Factors influencing food choice are not only based upon individual preferences, but are constrained by circumstances that are social (such as peer pressure), cultural and economic. Objectives:To find out the relation of adolescent's food habit with their socio-demographical condition. Methods: This was a cross-sectional type of descriptive study which was carried out among the students of Rev. Paul's high school, Gallamari, Khulna city with a view to assess the relation of adolescent's food habit with their socio-demographical condition. The sample size was 217 which were selected by systematic sampling method from adolescent (10 year-16 year) students of that school. Data was collected according to a partially structured questionnaire by face to face interview administered by interviewer. The frequency distributions of the entire variables were checked by using SPSS 16.0 windows program. Chi-square test was applied to find out the association between food habits of adolescents with the socio-demographic variables. Results: In this study it was found that only $21.7 \%$ of respondents have snacking (fast food/dairy food) behaviour at least three times per week. Among 217 of the respondents, 116 (53.5\%) were girls and 107 (49.3\%) were in between 13yr-14yr of age. There was no statistically significant positive relation in gender and age of respondents with eating habits. Among the respondents, 60 (27.6\%) fell into upper income group, out of them $25(41.7 \%)$ respondents likes to eat fast food/dairy food. Again 32(39.5\%) out of total 81 (37.3\%) respondents whose mothers worked outside of home liked to eat fast food/dairy food. The test revealed that there was statistically significant positive relation between economic condition and mother's occupation of respondents with their eating habits. It was found that 120 (55.3\%) had peer influence on their food choice. The study result statistically suggested that the more an adolescent is influenced by peers and friends, the more unhealthy will be the adolescent's eating habits. In summary, it would appear that peer emerged as the single best predictor of eating habits among adolescents. Conclusion: The findings of the result might be helpful for developing awareness among adolescents as well as parents and teachers regarding unhealthy behavior of adolescents to reduce the risk of unusual health outcome as well as to know about the associated factors which are related to unhealthy behavior, thus helpful to cut-off the factors from daily life style and become healthy citizen.
\end{abstract}

Key words: Adolescent, Food habit, Socio-demographic variables.

1. Dr. Silvia Paroi, MBBS, MPH, Assistant professor, Department of Community Medicine, Ad-din Akij Medical College, Khulna. Email: spl1bd@yahoo.com. Cell: 01711972415.

2. Dr. ABM Ariful Islam, MBBS, MPH, Assistant professor, Department of Community Medicine, Rangpur Army Medical College, Rangpur Cantonment, Rangpur.

3. Dr. Md. Abul Hasanat, MBBS, M. Phil, Associate Professor, Department of Physiology, Gazi Medical College, Khulna.

4. Dr. Fatema-Tuj-Zohora, MBBS, MPH, Lecturer, Department of Community Medicine, Kushtia Medical College, Kushtia. 
Introduction

Food habit refers to the way in which different people select, cook, serve and eat food that are available to them. The actions, reactions, and thoughts of an individual are influenced by other people or groups. Factors influencing food choice are not only based upon individual preferences, but are constrained by circumstances that are social, cultural and economic. Social influence may be represented by peer pressure, persuasion, marketing, sales, and conformity. ${ }^{1}$

Members of a social group depend on each other, share a common culture, and influence each other's behaviors and values. A person's membership in particular peer, work, or community groups impacts food behaviors. For example, a young person at a basketball game may eat certain foods when accompanied by friends and other foods when accompanied by his or her teacher.

Social influences on food intake refer to the impact that one or more persons have on the eating behaviour of others, either direct or indirect, either conscious or subconscious. Even when eating alone, food choice is influenced by social factors because attitudes and habits develop through the interaction with others. ${ }^{1}$

Research has shown that we eat more with our friends and family than when we eat alone and the quantity of food increases as the number of fellow diners grows. ${ }^{2}$

Social context includes both the people who have an impact on an individual's eating behaviour and the setting in which an individual consumes their dietary choice. People influence an individual's food choices directly and indirectly: buying food on behalf of an individual is a direct impact whilst learning from a peer's behaviour (conscious or subconscious) has an indirect impact. Social support (e.g. families) can have a beneficial effect on individual's food choice by encouraging and supporting healthy eating prac tices. The setting for food consumption (e.g. home, school, work, and restaurants) will affect food choice by the availability of food options.

Studies indicate that the level of education can influence dietary behaviour during adulthood. In contrast, nutrition knowledge and good dietary habits are not strongly correlated. This is because knowledge about health does not lead to direct action when individuals are unsure how to apply their knowledge. Furthermore, information disseminated on nutrition comes from a variety of sources and is viewed as conflicting or is mistrusted, which discourages motivation to change. Thus, it is important to convey accurate and consistent messages through various media, on food packages and of course via health professionals.

Health is influenced by the way in which people live, their access to health care, schools and leisure opportunities, their homes, communities and towns. Although socioeconomic inequalities are known to influence health-related behavior, little is known about the differential effects of health promotion across socioeconomic groups. ${ }^{3}$

As children enter adolescence, their choice of friends tends to ebb and flow. Some teens may be close to studious peers early on, and then may find themselves attracted to a more rebellious crowd. Others may feel right at home with extroverts and troublemakers because they provide the acceptance they seek. Existing research has shown that teenagers' behavior is linked to the peers they associate with. But until now, no study has examined how this pattern of peer association and behavior changes throughout adolescence. $^{4}$

The key driver for eating is of course hunger but what we choose to eat is not determined solely by physiological or nutritional needs. Some of the other factors that influence food choice include: 
- Biological determinants such as hunger, appetite, and taste

- Economic determinants such as cost, income, availability

- Physical determinants such as access, education, skills (e.g. cooking) and time

- Social determinants such as class, culture, family, peers and meal patterns

- Psychological determinants such as mood, stress and guilt Attitudes, beliefs and knowledge about food.

\section{Materials and methods}

This is a cross-sectional type of descriptive study which was carried out among the students of Rev. Paul's high school, Gallamari, Khulna city with a view to assess the relation of adolescent's food habit with their socio-demographical condition. The sample size was 217 which were selected by systematic sampling method from adolescent (10 year-16 year) students of that school. Data was collected according to a partially structured questionnaire by face to face interview administered by interviewer. This research work was followed by the ethical guidelines of the research such as -first of all the permission from authority of selected school was obtained to carry out the research work. Then the study, its purpose, objectives, methodology and benefits were explained to the respondents as well as their guardians, then informed consent was taken from respondents. The frequency distributions of the entire variables were checked by using SPSS 16.0 windows program. For tabular, charts and graphical representation, Microsoft word and Microsoft excel were used. Chi-square test was applied to find out the association between food habits of adolescents with the socio-demographic variables. Descriptive variables were explained with mean and standard deviation. Statistical significance was found by applying relevant statistical tests at appropriate probability level $(p=0.05$ or $p=$ 0.01).

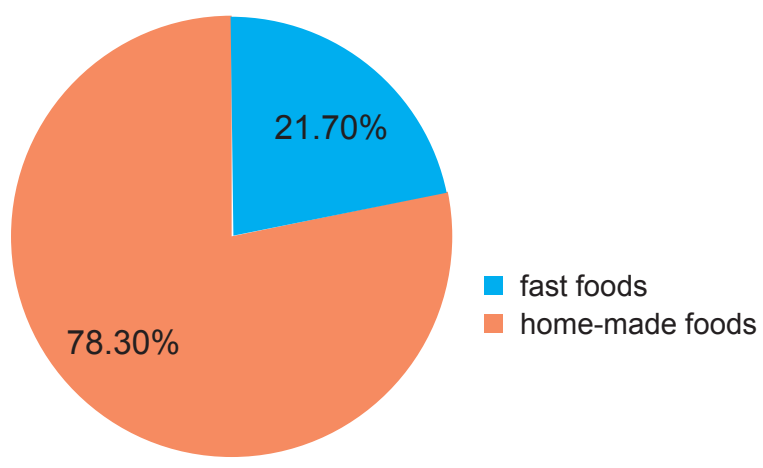

Figure 01: Distribution of the respondents by their food habit

It was observed that $21.70 \%$ respondents took fast food frequently and $78.30 \%$ had the practice to take home-made foods (Figure 01).

Table 01: Relation between food habits and gender among respondents

\begin{tabular}{|l|l|l|l|}
\hline \multirow{2}{*}{ Gender } & \multicolumn{2}{|c|}{ Foods } & \multirow{2}{*}{ Total } \\
\cline { 2 - 3 } & Fast food & $\begin{array}{c}\text { Homemade } \\
\text { food }\end{array}$ & \\
\hline Boy & $26(25.7 \%)$ & $75(74.3 \%)$ & $101(46.5 \%)$ \\
\hline Girl & $21(18.1 \%)$ & $95(81.9 \%)$ & $116(53.5 \%)$ \\
\hline Total & $47(21.7 \%)$ & $170(78.3 \%)$ & $217(100.0 \%)$ \\
\hline
\end{tabular}

$\square^{2}=1.86, \mathrm{df}=1, \mathrm{p}>0.05$

Among 217 of the respondents, 95 (81.9\%) girls and $75(74.3 \%)$ boys took home made food (Table 01). So it was found that girls took homemade food more than the boys. There was statistically no significant positive relation between gender of respondents and eating habits.

Table 02: Relation between food habits and age among respondents

\begin{tabular}{|l|l|l|l|}
\hline \multirow{2}{*}{ Age } & \multicolumn{2}{|c|}{ Foods } & \multirow{2}{*}{ Total } \\
\cline { 2 - 3 } & Fast food & $\begin{array}{c}\text { Homemade } \\
\text { foods }\end{array}$ & \\
\hline 10yr-12yr & $6(33.3 \%)$ & $12(66.7 \%)$ & $18(8.3 \%)$ \\
\hline 13yr-14yr & $22(20.6 \%)$ & $85(79.4 \%)$ & $107(49.3 \%)$ \\
\hline 15yr-16yr & $19(20.7 \%)$ & $73(79.3 \%)$ & $92(42.4 \%)$ \\
\hline Total & $47(21.7 \%)$ & $170(78.3 \%)$ & $217(100.0 \%)$ \\
\hline
\end{tabular}


The respondents were also grouped according to their age. About $85(79.4 \%)$ students aged between 13-14 years liked to have homemade foods (Table 02). The relationship between predictor and eating habit was statistically tested. The test revealed that there was statistically no significant positive relation between age of respondents and eating habits.

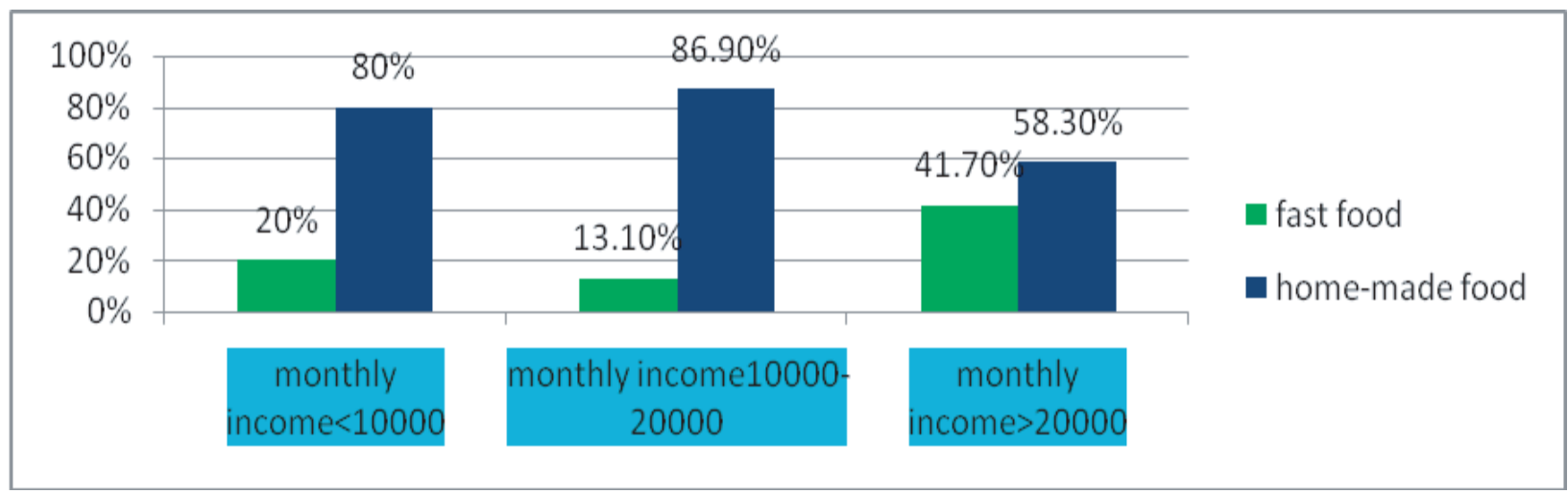

Figure 02: Relation between food habits and socio-economic condition among respondents

$\square^{2}=20.049, \mathrm{df}=2, \mathrm{p}<0.05$

Most of the respondents (86.90\%) liked to have homemade foods that fall in middle income group (monthly income <20000). Fast food eating habit about $41.70 \%$ falls in upper income group (monthly income $>20,000$ ). This Bar chart represents statistically significant positive relation between economic condition of respondents and eating habits. It was found that fast food/dairy food habit strongly related with socio-economic condition.

Table 03: Relation between mother's occupation and food habit among respondents

\begin{tabular}{|l|c|c|c|}
\hline \multirow{2}{*}{$\begin{array}{c}\text { Mother's } \\
\text { occupation }\end{array}$} & \multicolumn{2}{|c|}{ Foods } & \multirow{2}{*}{ Total } \\
\cline { 2 - 3 } & Fast food & $\begin{array}{c}\text { Homemade } \\
\text { food }\end{array}$ & \\
\hline Working outside & $32(39.5 \%)$ & $49(60.5 \%)$ & $81(37.3 \%)$ \\
\hline Housewife & $15(11.0 \%)$ & $121(89.0 \%)$ & $136(62.7 \%)$ \\
\hline Total & $47(21.7 \%)$ & $170(78.3 \%)$ & $217(100.0 \%)$ \\
\hline
\end{tabular}

$\square^{2}=24.26, \mathrm{df}=1, \mathrm{p}<0.05$

Out of 217 respondents 121 (89.0\%) respondents whose mothers are housewives, liked to have homemade foods (Table 03). It represents the relationship between mother's occupation and food habit of respondents which was statistically significant.

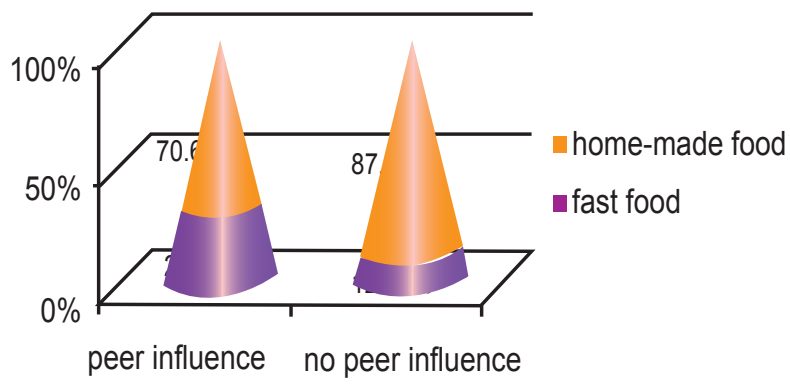

Figure 03: Relation between food habits and peer influence among respondents.

\section{$\square^{2}=8.92, \mathrm{df}=1, \mathrm{p}<0.05$}

It was observed that $87.60 \%$ respondents who have no peer influence like to have homemade foods (Figure 03). This represents the relationship between predictor and eating habit was statistically tested using the Pearson's correlation method. The test revealed that there was statistically significant positive relation between peer influence to respondents and eating habits.

\section{Discussion}

The frequent consumption of snacks and light meals is a recognizable aspect of teenage food behavior observed by Musaiger AO.5 In this study it was found that only $21.7 \%$ of respondents had fast foods. This finding was 
in line with the study carried out by Kurubaran Ganasegeran et al.6 where it was found that only $21.2 \%$ of respondents consumed fast food often. Chin and Nasir7 reported that only $4.7 \%$ of respondents visited fast food restaurants frequently. In contrast, Moy et al.8 reported that $60-70 \%$ of primary school students were fond of fast food.

Most of the respondents in this study had meals with their family or friends. It was observed that $87.60 \%$ respondents liked to have homemade foods with their family. This finding is in line with the study carried out by Kurubaran Ganasegeran et al.6 in which it was found that $81.1 \%$ took meal with their family. This is comparatively higher to that found by Yahia N et al.9 in which $42.7 \%$ of university students had meals with their families.

In our study it was found that $81.9 \%$ girls took homemade food more than the boys. Otherwise the findings carried out by Askari Majabadi $\mathrm{H}$ et al.10 in which it was found that about $62 \%$ boys liked to have fast food. In contrast Alimoradi et al.11 found that $51.7 \%$ boys and $55.6 \%$ students aged in between 14-16 years liked to have fast food.

Regarding mother's occupation it was found that most of the mothers were housewives and not working outside $(62.7 \%)$. Those respondents whose mothers were not working outside were more associated with homemade foods (about 89\%). Otherwise whose mothers are working outside are more associated with fast foods (39.5\%). This finding was in line with the study carried out by Alimoradi et al.11 where it was reported that $28.4 \%$ students liked to have fast food whose mothers are working outside.

In this study it was found that there is a linear regression with economic condition to food habits such as $41.7 \%$ respondents of upper income group (>20000 Tk./month) are more associated with fast foods. Askari Majabadi et al.10 found that $52.3 \%$ students of average income group are more associated with fast food.

In this study it was observed that about 55.3 $\%$ have strong peer influence and only about $44.7 \%$ reported to have no peer influence on their eating habit. Peer influence affected the eating habits of the adolescent students the most and was significant. Alimoradi et al.11 reported that $40.1 \%$ respondents had peer influence.

\section{Conclusion}

There are many influences on food choice which provide a whole set of means to intervene into and improve people's food choices. There are also a number of barriers to dietary and lifestyle change, which vary depending on life stages and the individual or group of people in question.

According to the results, peers negatively and significantly correlated with eating habits and also were the only predictor of eating habits. In general, most of the students in this study had healthy eating habits except in frequency of meals, fruit consumption, water intake and consumption of fried food. Social and economic factors were important determinants of eating habits. Nutritional education among adolescent students should be encouraged to promote healthier eating habits and lifestyles, as well as adherence to the healthier traditional food. It is a major challenge both to health professionals and to the public themselves to effect dietary change. Different strategies are required to trigger a change in behaviour in groups with different priorities. Campaigns that incorporate tailored advice that include practical solutions as well as environmental change are likely to succeed in facilitating dietary change. The result of this study will be helpful to parents as well as teachers to know about the factors associated with unhealthy life-style and behaviors among adolescents. This study will be helpful to the adolescents to 
know about those unhealthy life-style and behaviour and make them more aware about the associated factors.

This study finds out some of the most prominent factors influencing the life-style and behavior of adolescents, i.e. age, sex, parents' education and occupation, family income, and peer influence. Unhealthy life-style and behavior were found to be associated directly or indirectly more with the peer influence than with socio-economic status.

\section{References}

1. Anderson $A$, Hetherington $M$, Adamson $A$, et al.2003.The development of and evaluation of a novel school based intervention to increase fruit and vegetable intake in children (Five a Day The Bash Street Way). N09003. Report for the FSA, London. (see http://www.food.gov.uk/)

2. Feunekes GIJ, de Graaf C, Meyboom S and van Staveren WA.1998. Food choice and fat intake of adolescents and adults: associations of intakes within social networks. Preventive Medicine, 27: 645-656.

3. Giacomo L, Elena A, Andrea P, Rita S, Veronica M,Mariano VG.2014.Factors associated with unhealthy behaviours and health outcomes: a cross-sectional study among tuscan adolescents. International Journal for Equity in Health, 13:83-90.

4. Rahman MM, Ahmad SA, Karim MJ, Chia HA.2011.Oct.Determinants of smoking behaviour among secondary school students in Bangladesh. J Community Health,36(5):831-8.

5. Musaiger AO, Bader Z, Al-Roomi K, D'Souza R. 2011. Dietary and lifestyle habits amongst adolescents in Bahrain. Food \& Nutrition Research, 55:7122.
6. Kurubaran Ganasegeran, Sami AR Al-Dubai, Ahmad M Qureshi, Al-abed AA Al-abed, Rizal AM and Syed M Aljunid. 2012. Social and psychological factors affecting eating habits among university students in a Malaysian medical school: a cross-sectional study. Nutrition Journal, 11:48 doi: 10.1186/1475-2891-11-48.

7. Chin YS, Mohd NM. 2009. Eating behaviors among female adolescents in Kuantan District, Pahang, Malaysia.Pak J Nutr,8(4):425-432.

8. Moy FM, Johari S, Ismail Y, Mahad R, Tie FH, Wan Ismail WMA. 2009. Breakfast skipping and its associated factors among undergraduates in a public university in Kuala Lumpur. Mal J Nutr, 15(2):165-174.

9. Yahia N, Achkar A, Abdallah A, Rizk S. 2008. Eating habits and obesity among Lebanese university students. Nutr J, $7(32): 7 / 1 / 32$.

10. Askari Majabadi $H$, Solhi M, Montazeri A, Shojaeizadeh D, Nejat S, Khalajabadi Farahani F, Djazayeri A.2016 Mar. Factors Influencing Fast-Food Consumption Among Adolescents in Tehran: A Qualitative Study. Iran red cresent med J.6;18(3):e23890.doi: 10.5812/ ircmj. 23890.

11. Alimoradi, Jandaghi, Khodabakhshi, Maryam Javadi, and Seyed Amir Hossein Zehni Moghadam.2017 Jun 25.Breakfast and fast food eating behavior in relation to socio-demographic differences among school adolescents in Sanandaj Province, Iran.PubMed.Gov,9(6):4510-4515. doi: 10.19082/4510. 